\title{
Fast Paleogene Motion of the Pacific Hotspots From Revised Global Plate Circuit Constraints
}

\author{
Carol A. Raymond \\ Jet Propulsion Laboratory, California Institute of Technology, Pasadena, CA \\ Joann M. Stock \\ Seismological Laboratory, California Institute of Technology, Pasadena, CA
}

Steven C. Cande

Scripps Institution of Oceanography, University of California, San Diego, CA

\begin{abstract}
Major improvements in Late Cretaceous-early Tertiary Pacific-Antarctica plate reconstructions, and new East-West Antarctica rotations, allow a more definitive test of the relative motion between hotspots using global plate circuit reconstructions with quantitative uncertainties. The hotspot reconstructions, using an updated Pacific-hotspot kinematic model, display significant misfits of observed and reconstructed hotspot tracks in the Pacific and Indian Oceans. The misfits imply motions of $5-80 \mathrm{~mm} / \mathrm{yr}$ throughout the Cenozoic between the African-Indian hotspot group and the Hawaiian hotspot. Previously recognized misfits between reconstructed Pacific plate paleomagnetic poles and those of other plates might be accounted for within the age uncertainty of the paleomagnetic poles, and non-dipole field contributions. We conclude that the derived motion of the Hawaiian hotspot relative to the Indo-Atlantic hotspots between $61 \mathrm{Ma}$ and present is a robust result. Thus, the Pacific hotspot reference frame cannot be considered as fixed relative to the deep mantle. The bend in the Hawaiian-Emperor Seamount chain at $43 \mathrm{Ma}$ resulted from a speedup in the absolute motion of the Pacific plate in a westward direction during a period of southward migration of the hotspot. The relationship between the hotspot motion and plate motion at Hawaii suggests two possible scenarios: an entrainment of the volcanic sources in the asthenosphere beneath the rapidly moving plate while the hotspot source drifted in a plate-driven counterflow deeper within the mantle, or drift of the hotspot source which was independent of the plate motion, but responded to common forces, producing synchronous changes in hotspot and plate motion during the early Tertiary.
\end{abstract}

The History and Dynamics of Global Plate Motions Geophysical Monograph 121

Copyright 2000 by the American Geophysical Union

\section{INTRODUCTION}

For more than two decades, research has been carried out to determine the absolute motions of the Earth's tectonic plates. This work is motivated by the desire to investigate the fundamental driving forces of the plates, and motion of 
the deep mantle. Three main reference frames have emerged for defining past and present absolute plate motions: the hotspot, paleomagnetic, and mean-lithosphere frames (c.f. Jurdy, 1990). In the hotspot reference frame, first introduced by Morgan (1971), the motions of individual plates containing well-dated, progressive linear volcanic island chains, attributed to a set of fixed sources impinging on the bottom of a moving plate, are determined from the apparent motion of the plate over the sources (mantle plumes, or hotspots) (Minster and Jordan, 1978; Morgan, 1981; Jurdy and Gordon, 1984; Gordon and Jurdy, 1986). The motions of plates with strong expressions of timeprogressive volcanism ("hotspot tracks") are used to determine the motions of the other plates via plate circuits. In the work reported here, the plates for which motion relative to hotspots is well-determined are the Pacific plate (Lonsdale, 1988), the African plate and the Indian plate (Müller et al., 1993). Hotspot tracks on other plates are not considered robust enough to define their motion relative to their hotspots. To construct models of absolute plate motions in a hotspot reference frame, global plate reconstructions, or plate circuits, are used to connect every mobile plate to the fixed hotspots. These plate circuits include errors due to the quality of the data used to resolve relative plate motions.

Another important reference frame for examining absolute plate motions is the no-net-rotation, or mean-lithosphere, reference frame. In this treatment, the mean angular motion of all the tectonic plates is determined, then subtracted, from each individual plate's motion to arrive at the motions relative to this framework (Jurdy and Van der Voo, 1974; Jurdy, 1990). This reference frame can be defined based solely on the plate geometry and relative motions. A related reference frame, defined by Solomon and Sleep (1974), is the no-net-torque reference frame, in which the torques exerted by subducting slabs and ridges are either held in balance (uniform drag beneath the plates), or are balanced by non-uniform drag beneath the plates. Solomon and Sleep (1974) derive a set of plate motion models under different assumptions of the drag force, and no motion relative to the mantle, that do not differ greatly from absolute motion models derived under the fixed hotspot assumption. Some of these models result in a net rotation of the lithosphere.

The paleomagnetic reference frame is defined by the axial geocentric dipole (AGD) hypothesis, whereby all paleomagnetic poles are assumed to be representative of the ancient spin axis, because the Earth's field is assumed to be perfectly dipolar and the dipole axis to be collocated with the spin axis. This reference frame constrains only two of the three parameters of the plate relative to the spin axis (paleolatitude and paleoazimuth), leaving paleolongitude undetermined. This reference frame is the only means to establish the absolute plate motions in pre-Mesozoic time, and serves as an important alternative reference frame for
Mesozoic and Cenozoic time. Differences in motions of the plates within the paleomagnetic and hotspot reference frames have been cited as evidence of true polar wander, which refers to a motion of the entire solid earth relative to the spin axis. Therefore, the data sets which may be used to examine the kinematics, and thus dynamics, of plate motions through time are the relative motions of the plates, their motions relative to the hotspots, and paleomagnetic data which indicate the ancient position of the geomagnetic pole (paleopole) for a specific locality and time.

Significant revisions in relative plate motion models in the Southern Ocean, enabled by new and better fracture zone trends revealed by Geosat Geodetic Mission (GM) altimetry data (Sandwell and Smith, 1992), combined with significant new magnetic anomaly data sets, motivate a reanalysis of the global plate circuit connecting the Pacific plate to the rest of the world. Cande et al (1995) used dense magnetic anomaly data collected in a flowline corridor straddling the Pitman Fracture Zone on the southern Pacific-Antarctic Ridge, combined with the first new magnetic anomaly data in decades on the Marie Byrd land margin of Antarctica, to derive new Pacific-Antarctic finite rotations with smaller uncertainties. These new reconstructions differ significantly from earlier reanalyses of Stock and Molnar (1987), and Mayes et al. (1992), and define the plate kinematic evolution of the South Pacific basin with significantly higher resolution and confidence, although the pole path bears remarkable similarity to the original analysis of Molnar et al (1975).

These data have been combined with updated reconstructions of the Indian Ocean (Royer et al., 1988; Royer and Sandwell, 1989; Royer and Chang, 1991, Royer et al., 1997) to construct a new set of global plate circuits in order to test the hypothesis of fixed hotspots. The longevity and distinct geochemical character of hotspot magmas suggest that they tap regions of long isolated mantle (e.g. Anderson, 1995). Thus, the issue of the fixity of hotspots has important implications for the source region of the hot upwellings and the chemical heterogeneity of the mantle, as well as in defining a reference frame for evaluating plate driving forces.

It has long been recognized that the absolute motion of the Pacific plate derived under the assumption of fixed hotspots is inconsistent with independent evidence of the paleolatitudinal position of the Pacific plate through the Tertiary (Gordon and Cox, 1980a; Jurdy and Gordon, 1984; Acton and Gordon, 1994). Paleolatitude evidence from the distribution of equatorial sediment facies (van Andel, 1974; Suarez and Molnar, 1980; Gordon and Cape, 1981); paleomagnetic inclinations of seafloor rocks and sediments (Gordon, 1982); and paleomagnetic poles derived from inversions of seamount magnetic anomalies (Harrison et al., 1975), shape analysis of seafloor spreading anomalies (Schouten and Cande, 1976; Cande, 1976; Acton and Gordon, 1991; Petronotis et al., 1992; 1994), analyses of 
drilled basalts (Kono, 1980), and all of the above combined with sediment facies (e.g. Gordon and Cox, 1980b; Gordon, 1982), consistently indicate that the northward motion of the Pacific plate relative to the Earth's rotational (spin) axis was slower than the northward motion of the plate relative to the Hawaiian hotspot.

High-quality, independent data sets (sediment facies, seamount paleopoles, inclinations of drilled basalts and sediments), documenting the paleolatitudinal motion of the other non-Pacific plates, are not as complete. Nonetheless, Morgan (1981) proposed that motion occurred between the global hotspot reference frame and the spin axis since 60 $\mathrm{Ma}$, based on the misfit of paleomagnetic poles from globally distributed sites to the present north pole when reconstructed using absolute motions defined in the hotspot reference frame. The general lack of resolution of paleomagnetic poles, together with the possibility that they are corrupted by several types of systematic errors (remagnetizations, overprints and non-dipole components, e.g. Epp et al., 1983) leaves some ambiguity in the interpretation of the difference in motion of the Pacific plate relative to the hotspot and spin axis reference frames. We test the view that the hotspot tracks do not define a fixed reference frame, and interpret the results of our global plate circuit tests in terms of the rate of relative motion between the sources of the hotspot tracks, and the implications for paleomagnetic reconstructions.

Previous studies have come to conflicting conclusions concerning the fixity of hotspots. Gordon and Cox (1980a), Gordon and Jurdy (1986) and Acton and Gordon (1994) concluded from global plate circuit tests that the misfit of hotspot reconstructions, and the discordance between Pacific plate paleomagnetic poles and coeval poles reconstructed from the other continents, were consistent with the joint hypotheses of fixed hotspots and an unaccounted-for plate boundary in the South Pacific. The existence of a "missing" or unrecognized plate boundary between the North Pacific and East Antarctica was demonstrated by the extremely poor fit of the reconstructed hotspot tracks, indicating unrealistically large hotspot drift rates, as well as the non-closure of the local Pacific-Antarctic-Australia plate circuit in the early Tertiary, indicating motion between East and West Antarctica. These studies all favored a boundary between the North and South Pacific, active from early to mid Tertiary time, because of geometric constraints that limit the amount of motion that could be accommodated at an East-West Antarctic boundary.

Stock and Molnar (1987) examined the Pacific-Antarctic link of the global plate circuit and proposed that the PacificAntarctic finite reconstructions derived by Molnar et al. (1975) for Late Cretaceous and early Tertiary time actually described the motion between Antarctica and an oceanic plate separate from the Antarctic plate, which they named the Bellingshausen plate. They calculated Pacific-Antarctic rotations using only the early Tertiary Pacific plate seafloor spreading data, under the assumption of symmetric spreading. These rotations improved the agreement between the African hotspot frame and the Hawaiian track, particularly in reproducing the bend near $43 \mathrm{Ma}$. Molnar and Stock (1987) used this revised plate motion circuit, including quantitative uncertainties in the plate rotations, to argue for relative motions on the order of $10-20 \mathrm{~mm} / \mathrm{yr}$ between the Hawaiian hotspot source and the sources of major hotspot tracks in all the other ocean basins. Jurdy (1990) offered more evidence for these relative motions based on the divergence, in the mean-lithosphere reference frame, of the Pacific hotspots from the paleomagnetic (spin axis) and African hotspot reference frames through Cenozoic time.

\section{GLOBAL PLATE CIRCUIT TESTS OF HOTSPOT FIXITY}

The Pacific-Antarctic reconstructions of Cande et al. (1995) allow a far more rigorous test of the errors in the plate circuit and the fixity of hotspots. Global plate circuits exploit the concept of plate rigidity to predict the relative motion of a pair of plates by adding the relative motions of a series of intervening plates, which define the circuit. They are useful for estimating the history of relative motion between pairs of plates that share a convergent or transcurrent plate boundary, rather than a divergent spreading axis. Uncertainties in plate rotation parameters can be propagated through the circuit to accurately estimate the uncertainty in the derived rotation parameters; however, ignorance of a boundary in the circuit will invalidate the result. The new Pac-Ant reconstructions are inserted into plate circuits connecting the Pacific hotspots to the African and Indian hotspots, and vice-versa. The first link in the circuits is to reconstruct the starting plate (African, Pacific) to its past position relative to assumed fixed hotspot sources beneath it. We adopted the model of Müller et al. (1993) of the absolute motion of the Indian and African plates relative to their hotspot sources; this model combines hotspot tracks on the Indian, Antarctic and African plates with relative plate motion data to derive a consistent absolute plate motion model under the assumption that the hotspots beneath these plates are stationary relative to each other. The predictions of their model are consistent with the observed hotspot tracks in the Indian and Atlantic Oceans, indicating that the hotspot tracks define a single, consistent reference frame in this sector. It has been recognized for some time that the Kerguelen hotspot track is inconsistent with the joint hypotheses of fixed Indo-Atlantic hotspots and a hotspot location at Kerguelen Island. The solution has been to assume the Kerguelen source resides at the western edge of the northern Kerguelen plateau, beneath Skiff Bank (Duncan and Richards, 1991). However, a recent seismic survey shows a thick sediment cover in the presumed hotspot location (D. Müller, pers. comm.). It is likely that the source 
of the Kerguelen track lies near Kerguelen Island, indicating that the Kerguelen hotspot source is not fixed relative to the other Indo-Atlantic hotspot sources. Our reconstructions use the far west location for the Kerguelen source, which is most consistent with the fixed-hotspot assumption.

\section{A Revised Pacific-Hotspot Motion Model}

We use the Pacific-hotspot model of Lonsdale (1988) as a starting point for our reconstructions. Lonsdale's model is strongly constrained by data from the Louisville Ridge in the South Pacific, as well as data from the Hawaiian track. We made several modifications to Lonsdale's model to improve the fit to the better-constrained Hawaiian track without violating the fit to the Louisville track. First, we added a change in motion at chron 3 ( $5 \mathrm{Ma})$, corresponding to the change in Pacific plate absolute motion proposed by Engebretson et al. (1985). This is a simplification of the change in motion on the Pacific-Antarctic Ridge at chron 3A (5.9 Ma) observed by Cande et al. (1995). We then adjusted the pole and the rate of motion between $25 \mathrm{Ma}$ and $43 \mathrm{Ma}$, and increased the rate between $43 \mathrm{Ma}$ and $70 \mathrm{Ma}$, to achieve an excellent fit to both the position and ages of the Hawaiian volcanoes (Plate 1a). The resulting fit to the Louisville seamount chain (Plate 1b) is also good; however, a new zero-age position of the Louisville hotspot is required to register the predicted and observed tracks. The new Pacific-hotspot rotations are given in Table 1. Our inferred zero-age position for the Louisville hotspot source is at $51.5^{\circ} \mathrm{S}, 141.0^{\circ} \mathrm{W}$. There is no evidence (i.e., recent volcanism or seismicity) to support the inferred position of the Louisville source; however, it lies halfway between Lonsdale's position and the position inferred by Wessel and Kroenke (1997) using the "hot-spotting" technique $\left(53.5^{\circ} \mathrm{S}, 141.12^{\circ} \mathrm{W}\right)$.

We tested this new Pacific-hotspot model against the Duncan and Richards (1991) model and found little difference in the reconstructions; the conclusions we draw would be valid with either model.

\section{Revised Plate Circuits}

We used plate circuits to transfer the reference frame of the African/Indian hotspots to the Pacific basin, and calculated predicted tracks of the Hawaiian and Louisville hotspots. Similarly, we transferred the new Pacific-hotspot reference frame to the Indian Ocean and calculated predicted tracks of the Reunion and Kerguelen hotspots. The plate circuits used are listed in Table 2. A $100 \mathrm{~km}$ circular uncertainty in the position of the hotspot source was assumed to derive the uncertainties for the reference frame rotations. Traversing the circuit in both directions, using independently derived hotspot reference frame rotations for different plates, allows us to evaluate any systematic error which may be associated with these hotspot reference frame models. The detailed age progression and tight geometrical constraints of the Hawaiian track allow a more robust evaluation of the fit of the African/Indian hotspot model to the Pacific basin data. For the same reasons, the Pacific motion relative to the hotspots is arguably better determined than the model of the Indian plate motion relative to its hotspots.

The circuits listed in Table 2 comprise the revised Pacific-Antarctic rotations (Cande et al., 1995) and revised reconstructions of the Indian Ocean that incorporate Geosat constraints (Royer and Chang, 1991; Royer and Sandwell, 1989), as well as copious recent aeromagnetic data at chron 5 (Royer et al., 1997). Quantitative uncertainties estimated during the rotation fitting procedure are available for all the Pac-Ant reconstructions, and for Indian Ocean reconstructions at chrons 5, 6 and 13. Antarctica-India reconstructions for chrons older than 13 (Royer and Sandwell, 1989) did not include uncertainties; for these we estimated partial uncertainty rotations based on paleo-plate boundary geometry and conservative data uncertainties. The reconstructed tracks are referenced to the traditional location of the Hawaiian hotspot $\left(19.6^{\circ} \mathrm{N}, 204.5^{\circ} \mathrm{E}\right)$, our inferred position of the Louisville hotspot $\left(51.5^{\circ} \mathrm{S}, 141.0^{\circ} \mathrm{W}\right)$, an accepted position of the Reunion hotspot $\left(21.2^{\circ} \mathrm{S}, 55.6^{\circ} \mathrm{E}\right)$ and the position of the Kerguelen hotspot used by Duncan and Richards (1991) and Müller et al. (1993), which lies at the western edge of the Kerguelen plateau near Skiff Bank $\left(49^{\circ} \mathrm{S}, 63^{\circ} \mathrm{E}\right)$.

The new marine geophysical data from the South Pacific have documented a fragmented ridge system in the PacificAntarctic basin prior to chron $27(\sim 61 \mathrm{Ma})$. There appear to have been two or more ridges separating plates on the Antarctic side of the basin from the Pacific plate (Cande et al., 1995), as was suggested by Stock and Molnar (1987) when they proposed the Bellingshausen plate hypothesis. A reconstruction of the basin at chron 27 is shown in Figure 1, which was published by Heinemann et al. (1999). This reconstruction shows the geometry of the three plates (Marie Byrd Land, Bellingshausen, and Aluk) on the Antarctic margin. The boundary between the Bellingshausen plate and the Antarctic plate is known to be divergent or transtensional between the ridge and the margin, but its character upon reaching the continental margin at $\sim 245^{\circ} \mathrm{E}$ is unknown, and here presumed to be a subduction zone between $245^{\circ} \mathrm{E}$ and $270^{\circ} \mathrm{E}$. The eastern boundary of the Bellingshausen plate may have been a convergent or transcurrent boundary with the Aluk plate, based on deformation of the seafloor near Peter I Island seen in satellite and shipboard gravity, and multichannel seismic data (Gohl et al., 1997).

Previous Pacific-Antarctic reconstructions have relied heavily on data from the more well studied northern end of the basin, which we refer to as Pacific-Bellingshausen (PacBell), after Stock and Molnar (1987). We conclude that the previously poorly studied southern part of the basin 
Table 1. Finite Rotations for Pacific-Hotspot motion relative to the Pacific plate. Positive rotations are counterclockwise. Ages from Cande and Kent (1995).

\begin{tabular}{llccc}
\hline Chron & Age $(\mathrm{Ma})$ & Latitude & Longitude & Angle \\
\hline c3 & 5.0 & -56.50 & 104.90 & 4.70 \\
c5 & 10.83 & -65.98 & 108.75 & 9.24 \\
c6 & 21.16 & -70.45 & 111.79 & 17.43 \\
.- & 25.0 & -71.20 & 112.44 & 20.49 \\
c13 & 33.3 & -69.14 & 117.41 & 25.44 \\
c18 & 40.22 & -67.88 & 119.88 & 29.60 \\
-- & 43.0 & -67.46 & 120.64 & 31.28 \\
c20 & 43.87 & -66.87 & 119.71 & 31.43 \\
c21 & 47.86 & -64.25 & 116.15 & 32.60 \\
c24 & 53.25 & -60.86 & 112.54 & 34.14 \\
c28 & 63.3 & -55.19 & 108.08 & 37.47 \\
c31 & 68.68 & -52.51 & 106.42 & 39.39 \\
c33 & 78.78 & -48.08 & 104.10 & 43.22 \\
\hline
\end{tabular}

(spreading between Campbell Plateau and Marie Byrd Land) is a more likely candidate for Pacific-Antarctic spreading; thus our reconstructions differ significantly from previous ones. The Indian Ocean reconstructions also must take into account changing plate boundary geometry. For the reconstructions older than chron 13 we reconstructed Antarctica directly to India; however, for younger times, the deformation of the greater Indian plate necessitates linking the circuit from Antarctica to Africa to India. Deformation of the greater Indian (Indo-Australian) plate since chron 5 has been documented (Royer et al., 1997), and is included in our circuit calculations.

\section{East-West Antarctic Motion}

Many previous investigators have concluded that the lack of closure of early Tertiary global plate circuits, and the misfit of reconstructed hotspot tracks derived from them, could be explained by an unaccounted-for plate boundary between East and West Antarctica. Cenozoic extension along the Transantarctic Mountain front is evidence for such a boundary (Cooper et al., 1991; Wilson, 1995); however, strong constraints on the amount and timing of the extension are lacking. Gordon and Cox (1980a) tested the amount of motion that would be required to close the circuit if all motion occurred on an East-West Antarctic boundary. The resulting overlap of West Antarctica with South America in their model caused them to reject the possibility that East-West Antarctic motion could explain the misfit on the hotspot reconstructions.

Rotation parameters describing motion between East and West Antarctica have been derived from new magnetic anomaly and fracture zone data in the conjugate South Tasman Sea and in the Adare Trough in the northern Ross Sea, Antarctica (Cande, S. C., J. M. Stock, D. Müller and T. Ishihara, Cenozoic motion between East and West Antarctica, submitted to Nature). These new data allow a threeplate solution (with uncertainties) for Australia-East Antarctica-West Antarctica motions at chron 13o; the magnetic anomalies record motion between chron 80 and chron 200 (26 Ma to $44 \mathrm{Ma}$ ). We have performed global plate circuit reconstructions with and without inclusion of the motion between East and West Antarctica to illustrate how this previously poorly constrained leg of the circuit contributes to the agreement between the observed and reconstructed tracks.

The new marine geophysical data from the Adare Trough indicate significant motion began between East and West Antarctica at around $44 \mathrm{Ma}$. It is possible that, prior to that time, motion between East and West Antarctica was taken up at another boundary, possibly along the Transantarctic Mountains, which might affect the plate circuit through Antarctica. The main phase of extension within the Ross Embayment is thought to have occurred between 105-85 Ma based on geological evidence from the Transantarctic Mountains (Wilson, 1995) and Ross Sea (Cooper et al., 1991). Lawver and Gahagan (1994) reject the possibility of a significant amount of extension within the Ross Embayment during the early Tertiary, based on the fit between Marie Byrd Land and the Campbell Plateau offshore New Zealand at $86 \mathrm{Ma}$. Therefore, any significant amount of early Tertiary extension would have occurred west of Marie Byrd Land and the eastern Ross Sea, within the western Ross Sea. Cooper et al. (1991) propose a hiatus in deformation within the western Ross Sea between the formation of grabens in the Cretaceous and Eocene uplift of the Transantarctic Mountains, however, the ages of major unconformities within the Ross Sea are poorly resolved. The only possible evidence of a boundary in the vicinity of the Ross Sea, prior to spreading at the Adare Trough, is a maximum of $50 \mathrm{~km}$ of extension within the Iselin Trough, orthogonal to the Adare Trough, just east of the Iselin Bank. Such extension would have likely occurred between approximately $62 \mathrm{Ma}$ and $53 \mathrm{Ma}$. We conclude that we have captured the bulk of the motion between East and West Antarctica during the Tertiary by closing the Adare Trough. Only a small amount of further extension might have occurred, and this would have a negligible impact on the conclusions drawn from the reconstructions.

Table 2. Plate Circuit Parameters

\begin{tabular}{lll}
\hline & Reference & Chrons \\
\hline hs-pac & This paper & $5,6,13,18,21,24$, \\
& & $25,27,28,31$ \\
pac-ant & Cande et al., 1995 & $5,6,13,18,21,24$, \\
& & $25,27,28,31$, \\
want-eant & Cande et al., & 13,20 \\
& submitted & \\
ant-afr-ind & $\begin{array}{l}\text { Royer \& Chang, } \\
\text { 1991; Royer et al., }\end{array}$ & \\
& 1997 6, 13 \\
Royer \& Sandwell, & $18,21,24,28,31$ \\
int-aus(s. ind)- & 1989; Royer et al., \\
& $1988 ;$ Royer et al., \\
& 1997 & \\
\hline
\end{tabular}




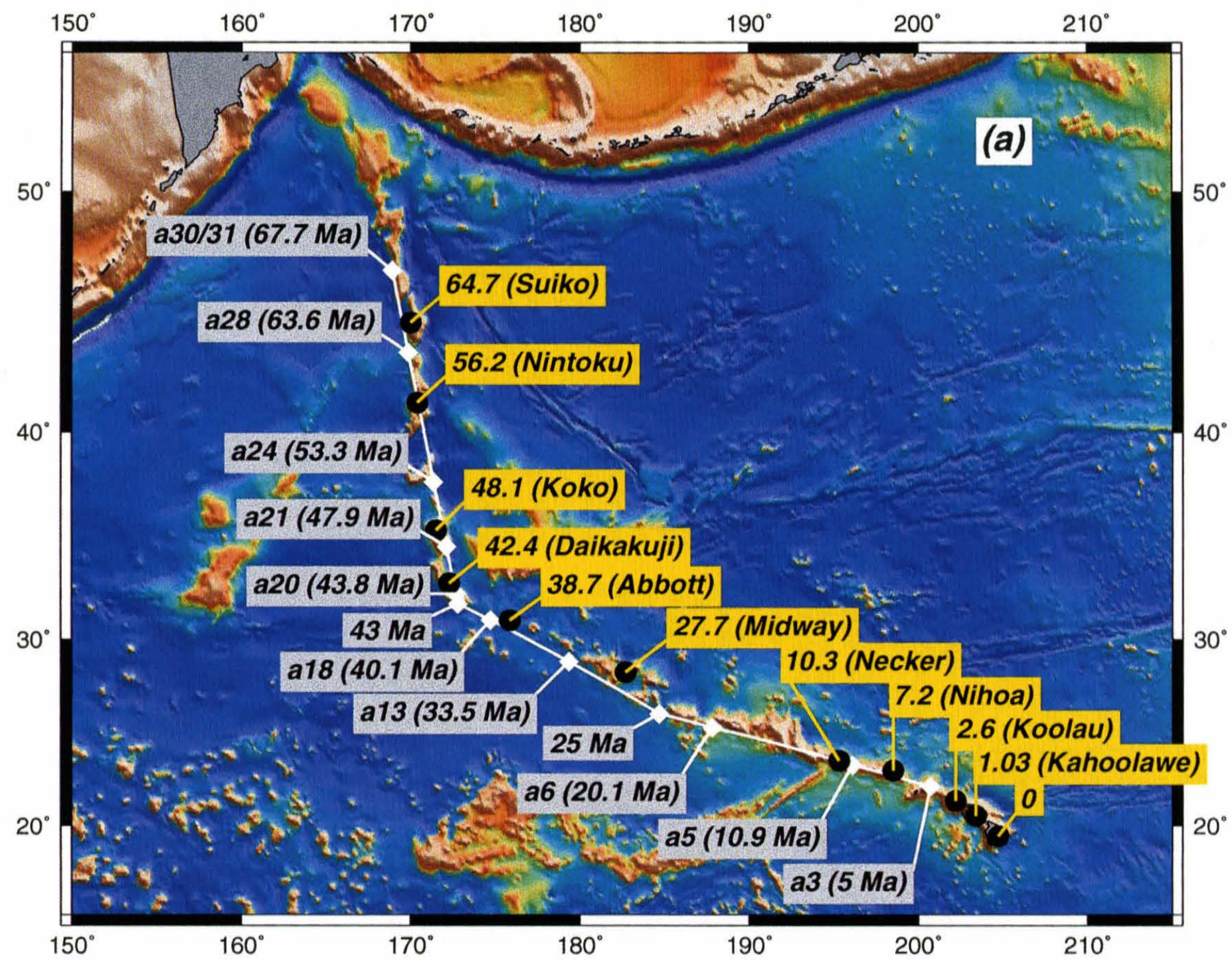

Plate 1. Revised Pacific-hotspot motion model shown as white line compared with the (a) Hawaiian-Emperor chain in the North Pacific, and (b) the Louisville seamount chain in the South Pacific. The annotated white diamonds give chrons and ages (from Cande and Kent, 1995) for the reconstruction. Annotated black dots give locations and ages of well-dated seamounts and islands along the chains (Clague and Dalrymple, 1989; Clague and Jarrard, 1973; Lonsdale, 1988). Image shows bathymetry from the ETOPO5 data set (NGDC, 1988). 


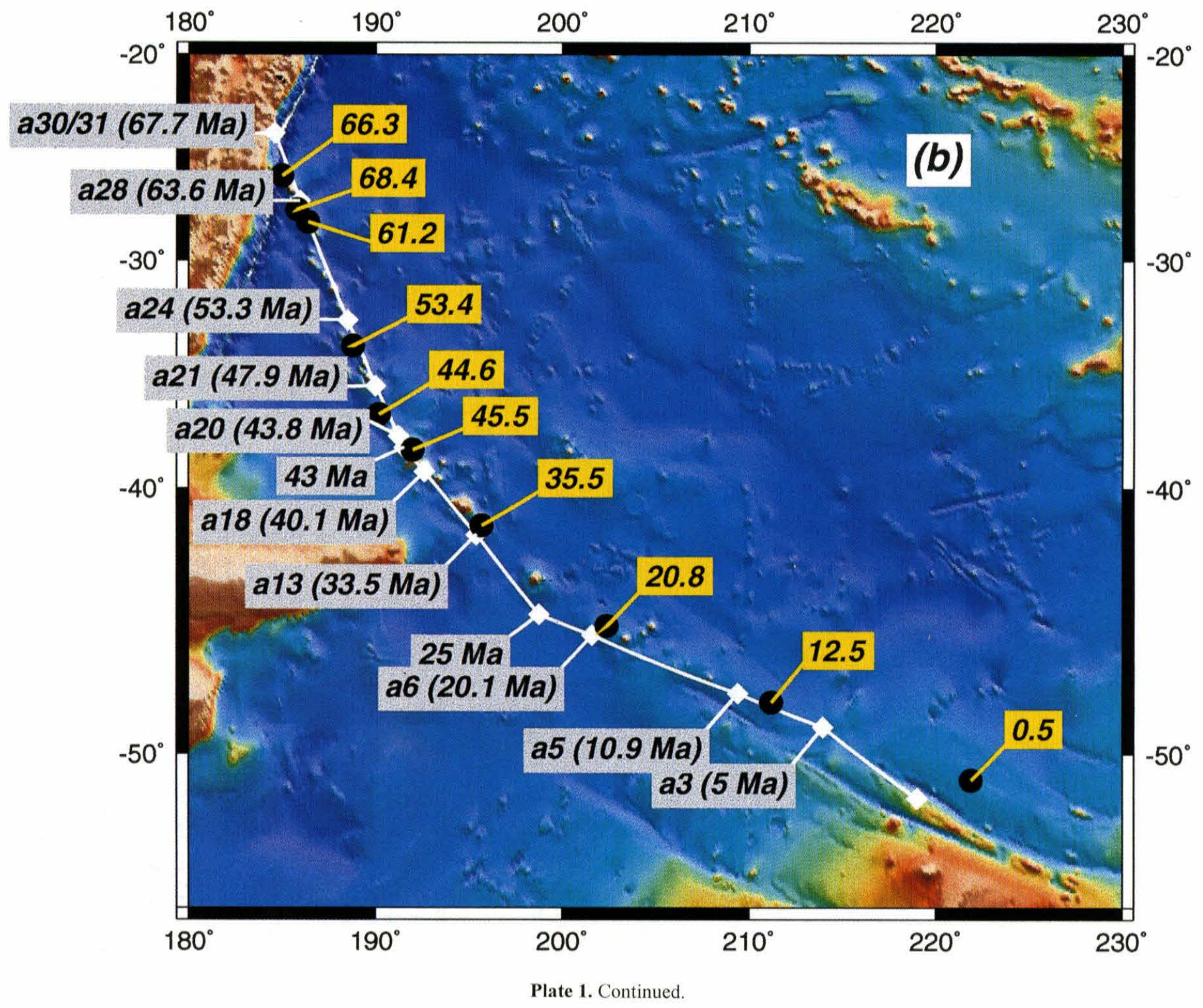




\section{RESULTS}

Tracks of the Pacific hotspots reconstructed in the IndoAtlantic reference frame to the Hawaiian-Emperor and Louisville chains, and the Indo-Atlantic hotspots reconstructed in the Pacific reference frame to the Chagos-Laccadive/Reunion and Kerguelen/Ninety East Ridge tracks are shown in Plate 2. Both sets of reconstructions clearly demonstrate a misfit that systematically increases with age between the reconstructed and observed tracks, regardless of the starting hotspot model. The most striking element of this misfit is the failure of the reconstructed track to reproduce the sharp bend in the Hawaiian-Emperor chain. Inclusion of East-West Antarctic motion improves the fit only slightly.

A subtler, yet persistent age misfit between the observed and reconstructed hotspot tracks is most clearly expressed for the well-dated Hawaiian chain. All the reconstructed points in the Pacific fall on seamounts that are younger than predicted, and the magnitude of the age discrepancy increases with the age. The opposite effect is observed for the reconstructed Indian points, although the misfit is not as clear because of the larger uncertainties.

\section{Motion of the Hawaiian Hotspot in the Indo-Atlantic Reference Frame}

The motion of the Hawaiian hotspot source relative to the Indo-Atlantic hotspot reference frame for intervals bounded by our well-resolved reconstructions is shown in Figure $2(a, b)$. The drift rate was calculated as latitudinal and longitudinal displacement over time since $68 \mathrm{Ma}$ to facilitate comparison to paleomagnetically-determined paleolatitude. The results show rapid westward drift of the hotspot source ( $73-80 \mathrm{~mm} / \mathrm{yr})$ during the Paleocene (69-56 $\mathrm{Ma})$, with a smaller southward component $(\sim 33-44 \mathrm{~mm} / \mathrm{yr})$. Our results for the oldest interval, 68-61 Ma, however, would be invalid if Campbell Plateau was moving with respect to the northern Pacific plate prior to the reorganization at $61 \mathrm{Ma}$. The drift changes to a southward motion at $\sim 44 \mathrm{~mm} / \mathrm{yr}$ during the interval from 56 to $43 \mathrm{~m} . \mathrm{y}$, slowing to $\sim 33 \mathrm{~mm} / \mathrm{yr}$ and becoming directed southwest between 43 and $33 \mathrm{Ma}$. A slow, dominantly eastward and southward drift persists to the present at rates of $5-20 \mathrm{~mm} / \mathrm{yr}$. These rates are remarkable in that the oldest rates (68-33 Ma) are many times faster than previous plate circuit estimates.

The recent drift rates ( $40 \mathrm{Ma}$ to present) generally agree with the predicted southeast drift for the Hawaiian and Louisville sources ( $12 \mathrm{~mm} / \mathrm{yr}$ and $9 \mathrm{~mm} / \mathrm{yr}$, respectively) derived by Steinberger and O'Connell (1998). These authors perform a numerical simulation of a 3-D flow field driven by plate motion to solve for hotspot migration in a no-netrotation reference frame. These authors also predict a simi$\operatorname{lar}(12 \mathrm{~mm} / \mathrm{yr})$ southeastward drift of the Kerguelen hotspot source since $40 \mathrm{Ma}$, but verv little motion of the Reunion hotspot $(2 \mathrm{~mm} / \mathrm{yr})$.

\section{Comparison to Motion of the Hawaiian Hotspot in the Spin Axis Reference Frame}

The derived rates support the fast southward drift deduced by Tarduno and Cottrell (1997) using paleomagnetic data on Late Cretaceous seamounts in the Emperor chain. These authors attribute the latitudinal discrepancy between the paleolatitudes of Detroit seamount $(81 \mathrm{Ma})$ and Suiko seamount $(65 \mathrm{Ma})$ and the present latitude of the Hawaiian hotspot to southward motion of the Hawaiian hotspot. Although they consider true polar wander (TPW) as a possible explanation for the Suiko-Hawaii latitudinal discrepancy, they reject TPW as a possible cause of the Detroit paleolatitude discrepancy because continental paleomagnetic data predict less, not more, TPW during this interval. They suggest southward motion of the sources of the seamounts, relative to a spin axis reference frame, of $30-50$ $\mathrm{mm} / \mathrm{yr}$ between 81 and $43 \mathrm{Ma}$, with possible rates as high as $64 \mathrm{~mm} / \mathrm{yr} \pm 43 \mathrm{~mm} / \mathrm{yr}$. These rates agree well with our estimates of southward motion of the hotspot source, relative to the Indo-Atlantic hotspot reference frame, of 44 $\mathrm{mm} / \mathrm{yr}, 33 \mathrm{~mm} / \mathrm{yr}$, and $42 \mathrm{~mm} / \mathrm{yr}$ for the intervals $68-61$ $\mathrm{Ma}, 61-56 \mathrm{Ma}$, and 56-43 Ma, respectively.

An independent estimate of southward drift of the Hawaiian hotspot source comes from a paleomagnetic pole determined by a comprehensive analysis of the skewness of anomaly 25r (Petronotis et al., 1994). By comparing their skewness pole to other paleomagnetic and sediment facies data, Petronotis et al. (1994) conclude that the Pacific plate was nearly stationary relative to the spin axis during the Eocene. They estimate a southward drift of the hotspot source of $52 \pm 24 \mathrm{~mm} / \mathrm{yr}$ between 57 and $39 \mathrm{Ma}$, corresponding to our southward drift estimate of $42 \mathrm{~mm} / \mathrm{yr}$ between 56 and $43 \mathrm{Ma}$. An analysis of the skewness of anomaly 32 further suggests that the rapid southward hotspot drift began earlier, with drift rates of $64 \mathrm{~mm} / \mathrm{yr}$ between 73 and $57 \mathrm{Ma}$ (Petronotis and Gordon, 1999).

Thus, a somewhat coherent picture of the latitudinal drift of the Hawaiian hotspot source is emerging from several lines of evidence summarized above. The favored scenario is for fast southward drift of the hotspot source (roughly 40$50 \mathrm{~mm} / \mathrm{yr}$ ) during the Paleocene and Eocene. Only very minor southward drift occurred post-late Eocene.

Quantitative uncertainties for the rotation parameters used in the global plate circuit yield error ellipses for the position of the hotspot track predicted by the reconstructions. The step of calculating the hotspot source drift at Hawaii from measuring the displacement of the observed and reconstructed track does not easily yield quantitative errors. The errors due to the uncertainty in the reconstructed positions can be visualized from the ellipses on the reconstructed points. However, because we are comparing the 


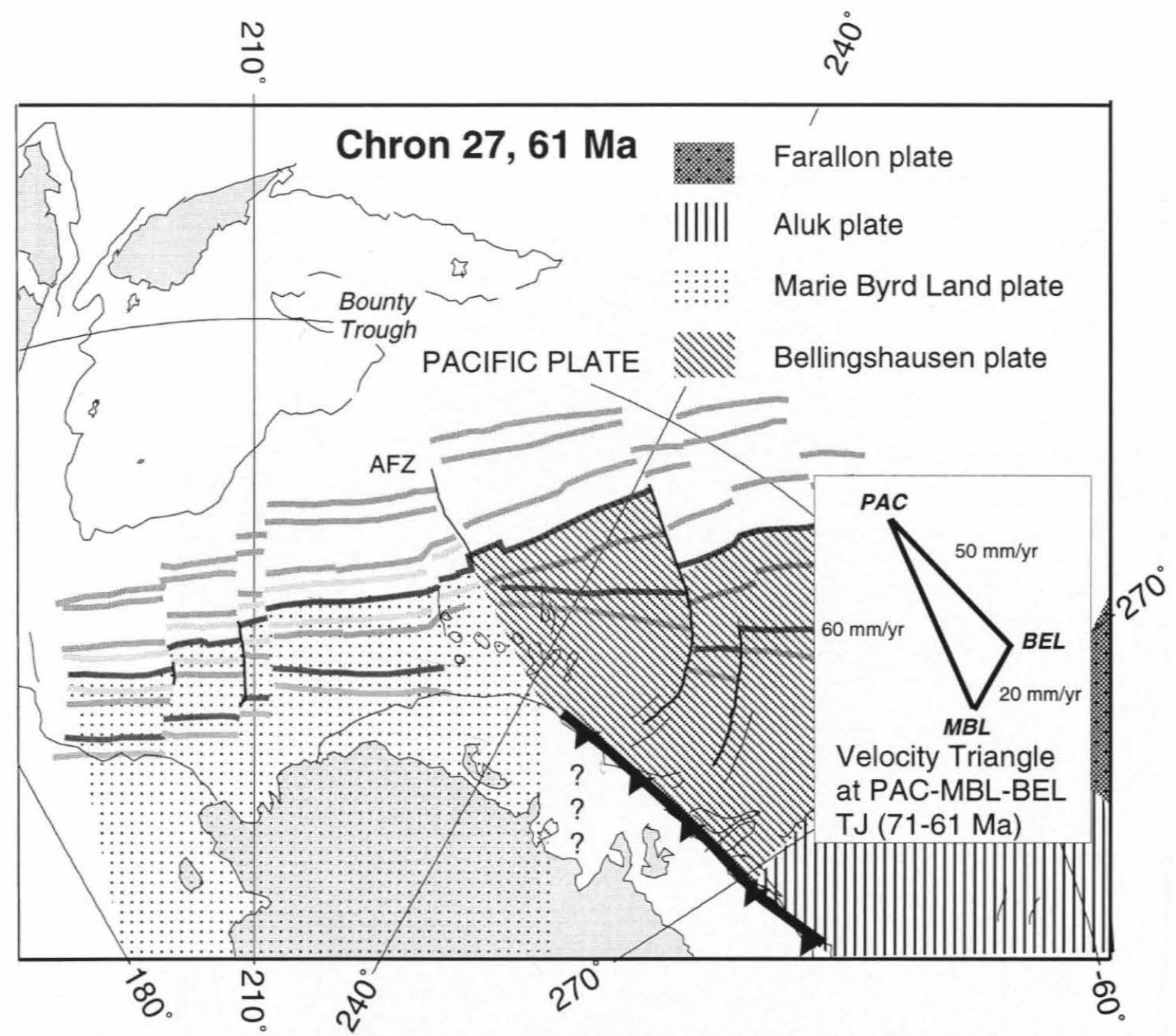

Figure 1. Reconstruction of the South Pacific Basin at chron 27 (61 Ma) showing the locations of the Pacific, Bellingshausen, Marie Byrd Land, Aluk and Farallon plates (from Heinemann et al., 1999). Schematic magnetic lineations are shown to illustrate the evidence for the separate Bellingshausen and Marie Byrd Land plates on the Antarctic margin. The Campbell Plateau is shown in the upper left corner, attached to the reconstructed North Island of New Zealand, and the location of the Bounty Trough within the Campbell Plateau is labeled.

ages of the anomalies with the ages of the dated volcanic edifices, the uncertainty in the age of both types of data contributes to the error in the derived drift rates. It is difficult to quantify this error, but we have observed that the drift rate results are sometimes quite sensitive to the ages assigned to the anomalies, since they are being compared to fixed ages for the volcanoes. Also, solving for the drift with a very narrow time window, such as for an individual anomaly, results in noise in the derived rates. The rather smooth nature of the variation in drift rate that we show for the selected intervals indicates this noise has been suppressed, and errors caused by the uncertainty in the magnetic chron ages have been reduced.

\section{DISCUSSION}

Before the misfits in the hotspot reconstructions can be interpreted unequivocally as evidence for inter-hotspot motion, we must consider the possibility that a systematic error remains in the plate circuit. It seems unlikely that errors in the reconstructions of plates to their respective hotspots contribute significantly to the misfit because we see similar misfits using two completely independent starting models (one for Indo-Atlantic hotspots and one for Pacific hotspots). We have included a new East-West Antarctica rotation with quantitative uncertainties that is constrained by seafloor data, thereby eliminating that link 


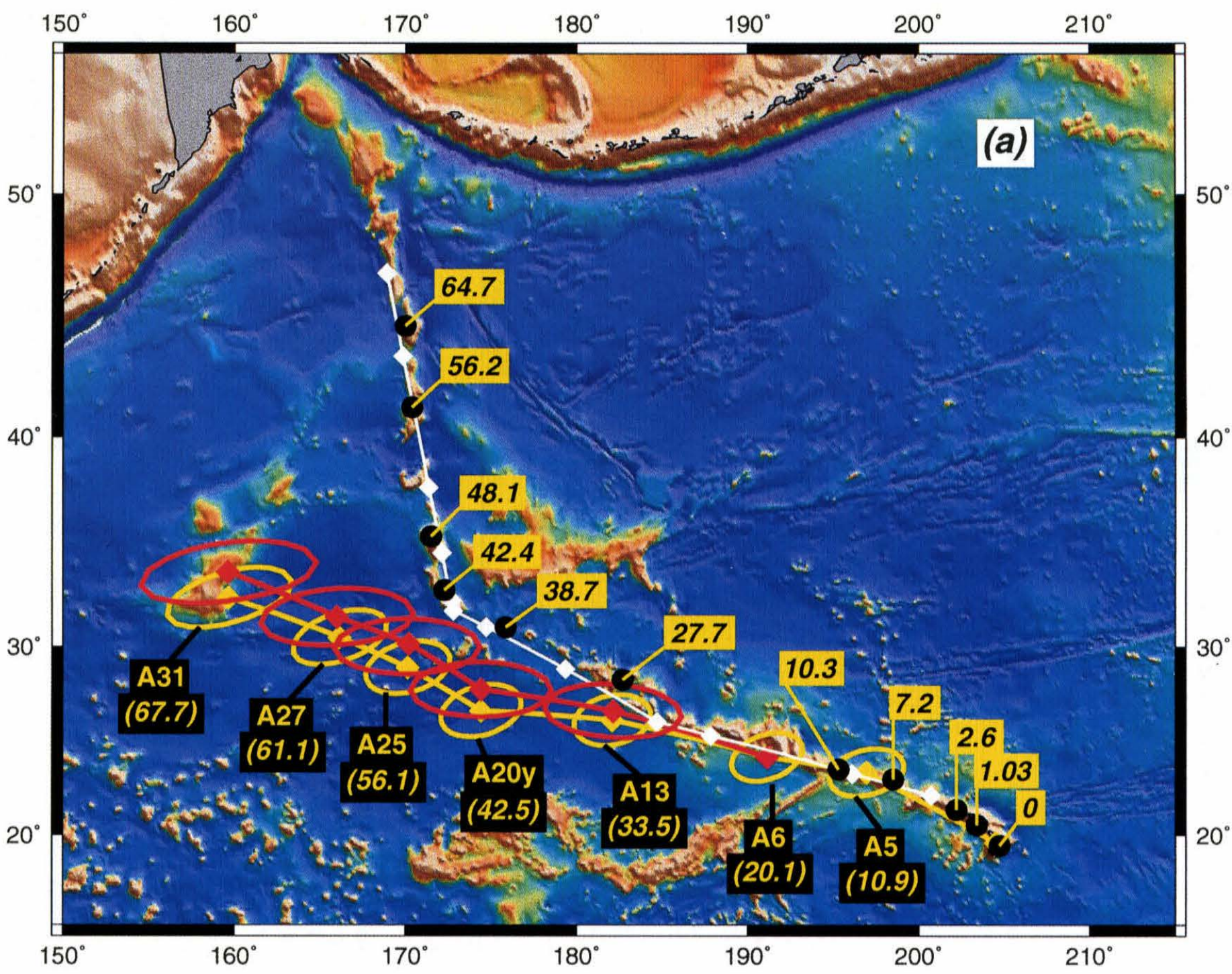

Plate 2. Reconstructions of Pacific-hotspot motion in the Indo-Atlantic reference frame to (a) the HawaiianEmperor chain and (b) the Louisville chain, and (c) reconstructions of Indo-Atlantic hotspots in the Pacific frame to Reunion and Kerguelen, superimposed on ETOPO5 bathymetry image. Reconstructed tracks shown in yellow with quantitative plate reconstruction error ellipses; chrons and ages as shown. Red track includes East-West Antarctic motion. 


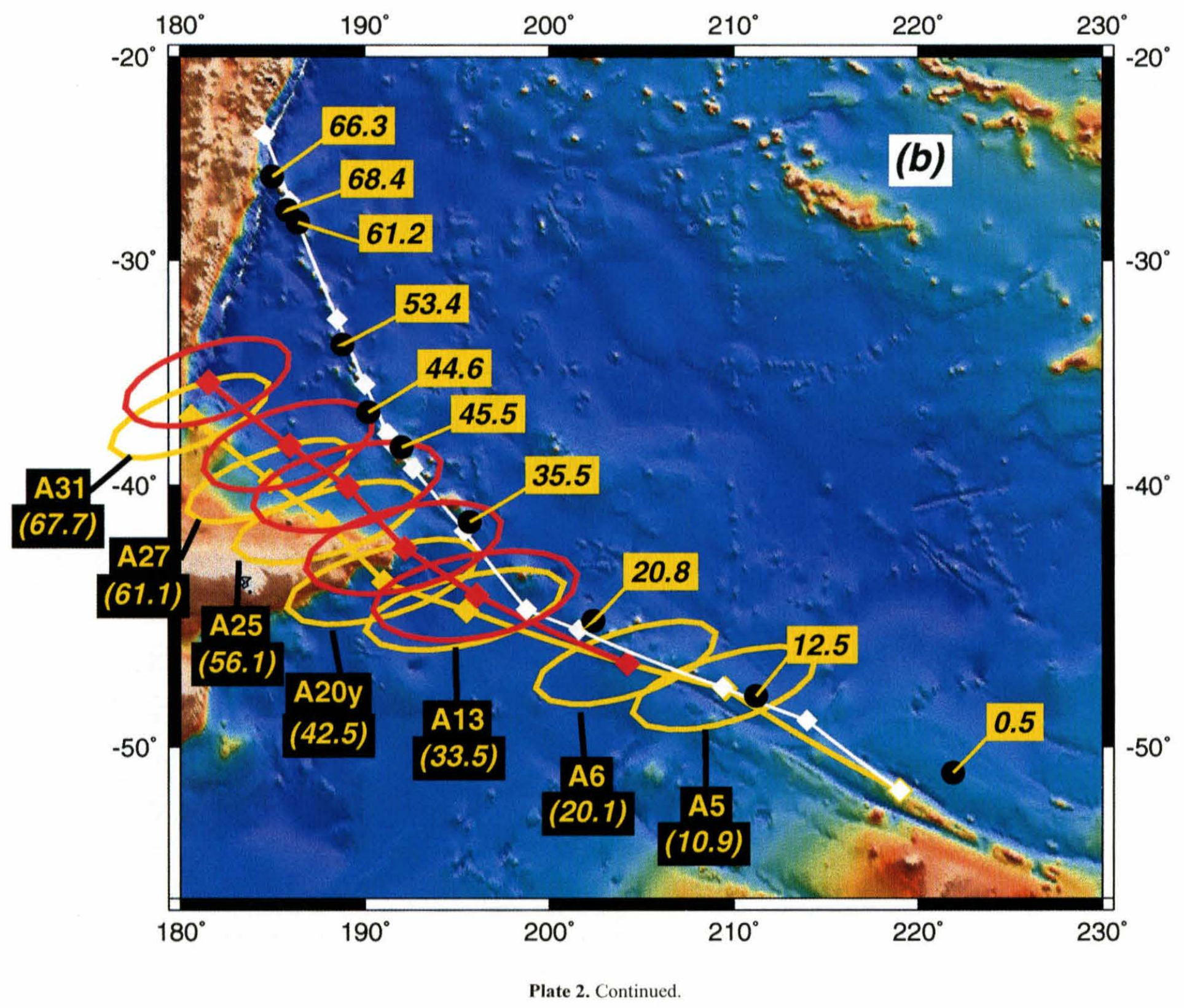



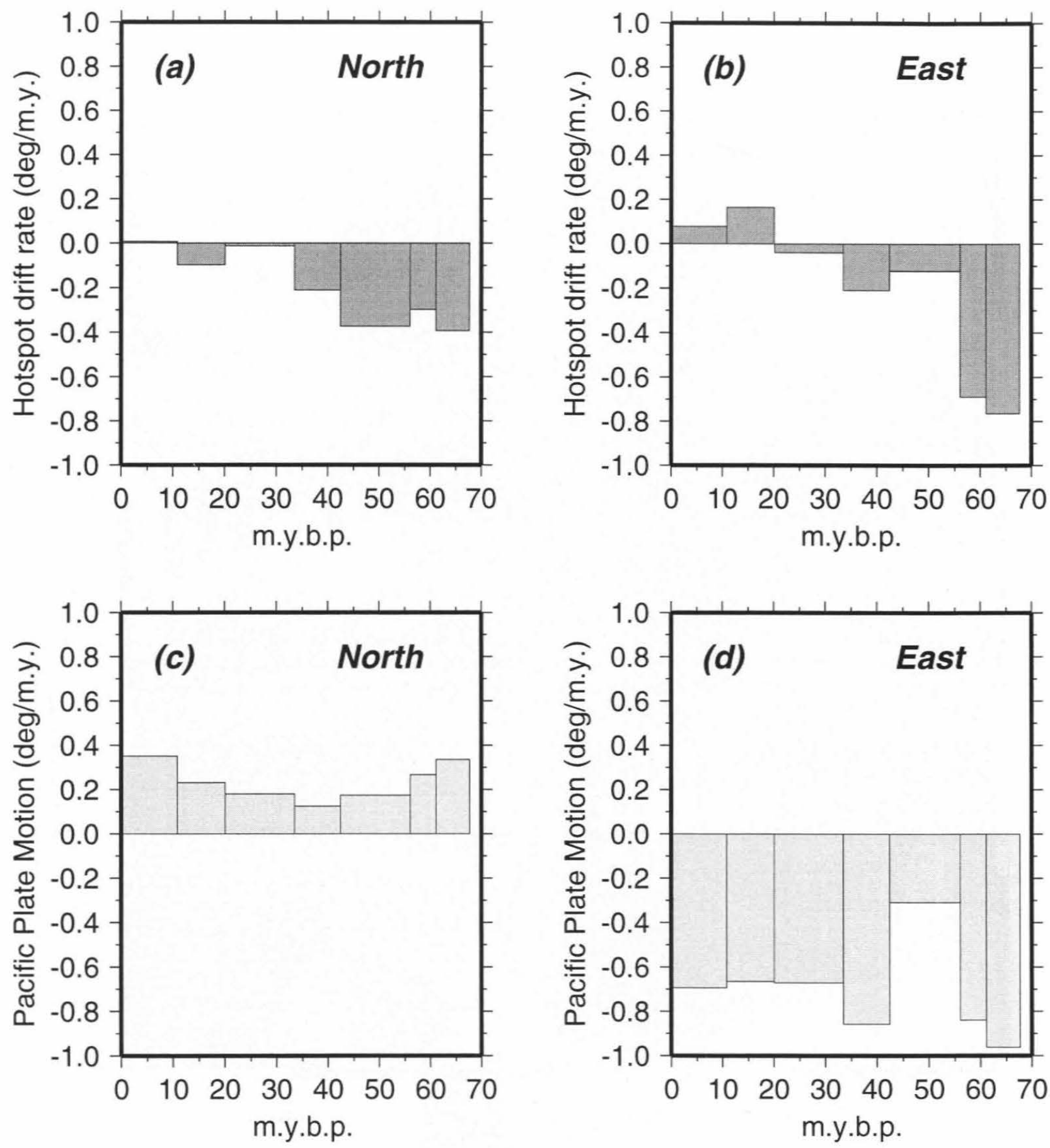

Figure 2. Inferred drift rate of the Hawaiian hotspot versus time in latitude (a) and longitude (b) compared to Pacific plate motion in the Indo-Atlantic fixed-hotspot reference frame, calculated at the location of the Hawaiian hotspot, in latitude (c) and longitude (d) versus time. (a) hotspot drift rate north in deg./m.y.; (b) hotspot drift rate east in deg./m.y.; (c) Pacific plate motion north in deg./m.y.; (d) Pacific plate motion east in deg./m.y. 
as a major source of error. It is possible that the misfit in the reconstructions in early Tertiary time are caused by an unrecognized plate boundary within the Pacific plate, as proposed by Gordon and Cox (1980a), Gordon and Jurdy (1986) and Acton and Gordon (1994), such as between the Campbell Plateau and the north Pacific, which would then invalidate our Pac-Ant reconstructions. Detailed geophysical observations from the south Pacific are needed to address this possibility. Although an unrecognized plate boundary is possible during the early Tertiary, evidence for such a boundary of mid to late Tertiary age, where copious constraints on plate reconstructions exist, is lacking, yet we still observe significant misfits up to the present.

The main argument for an unrecognized plate boundary remaining in the circuit comes from global plate circuit reconstructions of paleomagnetic data, as were done most recently by Acton and Gordon (1994). While that study included rigorous treatment of the errors in the paleomagnetic data and the reconstructions, there are several possible additional systematic errors in the paleomagnetic data that could contribute to the discrepancies observed in their reconstructions. One possible source of error is non-dipole field components. Acton and Gordon (1994) recognize that a $4 \%$ geocentric axial quadropole component would contribute an additional $2^{\circ}$ of uncertainty to their reconstructions. The systematic shift of the high latitude poles (Greenland, Antarctica) away from the Pacific pole at $58 \mathrm{Ma}$ suggests that eccentricity of the dipole field might be contributing to the misfit. Another unmodeled error is contributed by the age uncertainty in the derived poles. For instance, the reconstructed position of the $65 \mathrm{Ma}$ Indian paleopole moves $2.5^{\circ}$ closer to the Pacific 65 Ma pole when reconstructed at $67 \mathrm{Ma}$ (the older edge of the tightly-constrained age uncertainty on the Indian pole) because the Pacific plate is moving northward at that time. Consideration of these additional sources of error casts some doubt that the paleomagnetic reconstructions provide a compelling argument for a problem in the plate circuit.

\section{Implications for Mantle Dynamics}

Our new reconstructions imply that the motion of the Hawaiian hotspot source, relative to the Indo-Atlantic hotspots (Fig 2b) changed significantly at $56 \mathrm{Ma}$, when the direction of motion shifted from $\sim 245^{\circ}$ to $198^{\circ}$, and motion slowed from 80 to $44 \mathrm{~mm} / \mathrm{yr}$. No dramatic change in motion of the hotspot source is observed at the time of the Hawaiian-Emperor bend at $43 \mathrm{Ma}$. The motion of the Pacific plate in the Indo-Atlantic hotspot reference frame also shows no dramatic change in direction at 56 or $43 \mathrm{Ma}$. The remarkable bend in the Hawaiian-Emperor chain at 43 $\mathrm{Ma}$ is thus a consequence of a significant increase in the speed of westward plate motion ( $57 \mathrm{~mm} / \mathrm{yr})$, decoupling of the westward hotspot source motion from the plate motion, and a slight slowing of the southward hotspot drift (Fig 2), as viewed in the Indo-Atlantic fixed-hotspot reference frame.

An intriguing relationship is observed between the motion of the Hawaiian hotspot and that of the Pacific plate in the Indo-Atlantic reference frame. The hotspot track implies strong westward drift of its source, in the same direction as the motion of the plate between 68-56 Ma. The westward drift of the hotspot source slows dramatically at $56 \mathrm{Ma}$ in concert with a change in plate speed, and then the source continues to drift slowly west between 56 and $33 \mathrm{Ma}$. The latitudinal drift of the hotspot is opposite to the plate motion between 68 and $33 \mathrm{Ma}$, as was previously noted by Petronotis and Jurdy (1990), and of similar magnitude. A possible explanation for these observations is that the asthenosphere was coupled to the fast-moving plate and entrained the magmatic source of the hotspot track in a linear shear flow. At the same time, the deeper subasthenospheric source of the hotspot track was drifting south, most likely in a plate-driven return flow (Chase, 1979; Olson, 1987; Duncan and Richards, 1991; Morgan and Smith, 1992). Previous models which predict that plumes may become advected in mantle flow and their conduits may bend considerably from vertical, support this inference (Richards and Griffiths, 1988; Duncan and Richards, 1991; Steinberger and O'Connell, 1998). The rates shown in Fig 2 (a) and (b) were derived from examining the surface expression of the hotspot, which represents the integrated motion of the source beneath the surface. Therefore we can only speculate on how the source conduit might be moving at different levels within the mantle.

Although we cannot resolve varying motion of the hotspot source with depth, we can still infer such motions based on the observations. If the plate and the hotspot source were indeed coupled during the period from $\sim 68-43$ $\mathrm{Ma}$, as indicated by the strong correlation between westward plate motion and westward hotspot source motion, then the source of the Hawaiian hotspot (below the asthenosphere) may have actually drifted south faster than the rates calculated in Fig 2 (a). If the sub-asthenospheric hotspot conduit had its top sheared northward by northward plate motion, then the position of the surface expression of the hotspot would lie north of the source position at great depth. Assuming that the top of the source conduit moved north with the plate yields a (maximum) southward hotspot source drift rate of $60-80 \mathrm{~mm} / \mathrm{yr}$ between 68 and $43 \mathrm{Ma}$.

The interpretation of entrainment of the hotspot source beneath the plate is problematic, however, in that the correlation of westward rates of motion decreases between 56 and 43 Ma during a period of slow plate motion, but does not increase when the plate resumes moving rapidly westward post-43 Ma. If the entrainment did occur, a lower sublithospheric viscosity post-56 Ma may have enabled rapid changes in plate motion (Ratcliff et al., 1998), and also decoupled the plate motion and hotspot drift post-43 Ma 
372 FAST PALEOGENE MOTION OF THE PACIFIC HOTSPOTS



Plate 2. Continued. 
(Steinberger and O'Connell, 1998). Post-33 Ma, the hotspot drift is weak $(5-20 \mathrm{~mm} / \mathrm{yr})$, and slightly anti-correlated to plate motion, in general agreement with the prediction of Steinberger and O'Connell (1998).

To summarize, the evidence for synchronous changes in plate motion and hotspot drift between 68 and 43 Ma suggests that the motion of the plate may be controlling the motion of the hotspot source, including shearing of the source conduit beneath the plate and drift in a plate-driven return flow deeper within the mantle. Conversely, the motion of both the hotspot source and the plate may have been controlled by other events, such as changes in mantle flow patterns due to the approach and eventual destruction of ridges along the North American margin during the early Tertiary, and initiation of subduction in the western Pacific.

The fast Paleogene drift rates provide some constraints on the viscosity structure of the mantle beneath the Pacific during that time. The modeling results of Steinberger and O'Connell (1998) indicate that if the source conduit was indeed entrained in sub-lithospheric flow and/or subasthenospheric flow, then the viscosity should have been high enough in the upper mantle to allow advection of the density anomalies, but low enough to avoid overtilting of plume conduits. Steinberger and O'Connell (1998) suggest a viscosity higher than $3 \times 10^{19} \mathrm{~Pa} \mathrm{~s}$ and lower than $10^{21} \mathrm{~Pa} \mathrm{~s}$ to allow for the fast hotspot motion we infer within the upper mantle.

\section{CONCLUSIONS}

Reconstructions of the Pacific hotspots in the IndoAtlantic reference frame, and vice-versa, using updated plate rotations with quantitative uncertainties show significant and persistent misfit of the observed and reconstructed hotspot tracks. This misfit implies differential motion between the Pacific and Indo-Atlantic hotspot groups. Müller et al (1993) show no resolvable motion within the Indo-Atlantic hotspot group, except for a constrained fit to the Kerguelen track discussed previously. Our revised Pacific-hotspot model fits both Louisville and Hawaii, indicating little relative motion between Pacific hotspots, and suggesting that the misfit in the reconstructions is caused by motion of the Pacific hotspot group relative to the Indo-Atlantic group, although small relative motions within each group cannot be excluded. The plate circuit we used is still in question prior to $61 \mathrm{Ma}$ because of remaining uncertainty about the plate kinematics of the southwest Pacific basin; however, the existence of a misfit throughout the Tertiary is incontrovertible.

The plate circuit test indicates drift of the Hawaiian hotspot relative to Indo-Atlantic hotspots of with rates as high as $80 \mathrm{~mm} / \mathrm{yr}$. Latitudinal drift of the Hawaiian hotspot relative to the Indo-Atlantic hotspots agrees with drift relative to the spin axis (Gordon and Cox, 1980a; Gordon and Cape, 1981; Petronotis et al., 1994; Tarduno and Cottrell,
1997). We conclude, because of possible systematic. errors and scarcity of data, that paleomagnetic evidence for coherent motion between the spin axis and a fixed hotspot reference frame is less compelling than the evidence for southward drift of the Hawaiian hotspot relative to both the spin axis and the other hotspots, a conclusion that was also reached by Jurdy (1990).

The relationship between the Hawaiian hotspot track and the Pacific plate motion, referenced to the Indo-Atlantic hotspots and observed at Hawaii, suggests a coupling between plate motion and drift of the hotspot source at shallow levels between 68 and $43 \mathrm{Ma}$, with coeval fast southward drift of the source at a deeper level. These observations may be interpreted as indicating the influence of the plate motion on the motion of the hotspot source, or alternatively, as showing the influence of mantle dynamics on both the hotspot and the plate motion. Further modeling is needed to refine the estimates of hotspot drift and absolute plate motion for the Pacific plate to develop models which link the kinematics and dynamics.

Acknowledgments. This work benefited from discussions with many people, especially Richard Gordon, Bernhard Steinberger, Todd Ratcliff, Dietmar Mueller, Chuck DeMets and Gary Acton. Reviews by B. Steinberger and an anonymous reviewer improved the manuscript. GMT software was used to produce the figures (Wessel and Smith, 1991). This research was supported by NSF-OPP-93-17318. Part of the work was performed at the Jet Propulsion Laboratory, California Institute of Technology, under contract to the National Aeronautics and Space Administration. California Institute of Technology, Division of Geological and Planetary Sciences, Contribution number 8688 .

\section{REFERENCES}

Acton, G. D. and R. G. Gordon, A 65 Ma paleomagnetic plate for the Pacific plate from the skewness of magnetic anomalies 27r-31, Geophys. J. Int., 106, 407-420, 1991.

Acton, G. D. and R. G. Gordon, Paleomagnetic tests of Pacific plate reconstructions and implications for motion between hotspots, Science, 263, 1246-1254, 1994.

Anderson, D. L., Lithosphere, asthenosphere and perisphere, Rev. Geophys., 33, 125-149, 1995.

Cande, S. C., A pelaeomagnetic pole from Late Cretaceous marine magnetic anomalies in the Pacific, Geophys. J. R. Astron. Soc., 44, 547-566, 1976.

Cande, S. C., C. A. Raymond, J. Stock and W. F. Haxby, Geophysics of the Pitman fracture zone and Pacific-Antarctic plate motions during the Cenozoic, Science, 270, 947-953, 1995.

Cande, S. C. and D. V. Kent, Revised calibration of the geomagnetic polarity timescale for the Late Cretaceous and Cenozoic, J. Geophys. Res., 100, 6093-6095, 1995.

Chase, C. G., Asthenospheric counterflow: a kinematic model, Geophys. J. R. Astron. Soc., 56, 1-18, 1979.

Clague, D. A. and G. B. Dalrymple, Tectonics, geochronology and origin of the Hawaiian-Emperor chain, in The Eastern 
Pacific Ocean and Hawaii, vol. N of The Geology of North America, edited by E. L. Winterer, D. M. Hussong, R. W. Decker, Geological Society of America, Boulder. CO, pp. 188-217, 1989.

Clague, D. A. and R. D. Jarrard, Tertiary pacific plate motion deduced from the Hawaiian-Emperor chain, GSA Bull. 84 , 1135-1154, 1973.

Cooper, A. K., F. J. Davey and K. Hinz, Crustal extension and origin of sedimentary basins beneath the Ross Sea and Ross Ice Shelf, Antarctica, in Geological Evolution of Antarctica, edited by M. R. A. Thomson, J. A. Crame and J. W. Thomson, pp. 285-291, Cambridge University Press, New York, 1991.

Duncan, R. and M. A. Richards, Hotspots, mantle plumes, flood basalts and true polar wander, Rev. Geophys., 29, 3150,1991 .

Engebretson, D. C., A. Cox and R. G. Gordon, Relative motions between oceanic and continental plates in the Pacific Basin, Geol. Soc. Am. Spec. Pap. 206, 59 pp., 1985.

Epp, D., W. W. Sager, F. Theyer and S. R. Hammond, Hotspotspin axis motion or magnetic far-sided effect?, Nature, 303, 318-320, 1983.

Gohl, K., F. Nitsche and H. Miller, Seismic and gravity data reveal Tertiary interplate subduction in the Bellingshausen Sea, southeast Pacific, Geology, 25, 371-374, 1997.

Gordon, R. G. and C. D. Cape, Cenozoic latitudinal shift of the Hawaiian hotspot and its implications for true polar wander, Earth Plan. Sci. Lett., 55, 37-47, 1981.

Gordon, R. G. and A. Cox, Paleomagnetic test of the early Tertiary plate circuit between the Pacific basin plates and the Indian plate, J. Geophys. Res., 85, 6534-6546, 1980a.

Gordon, R. G. and A. Cox, Calculating paleomagnetic poles for oceanic plates, Geophys. J. R. Astron. Soc., 63, 619-640, $1980 \mathrm{~b}$.

Gordon, R. G., The late Maastrictian paleomagnetic pole of the Pacific plate, Geophys. J. R. Astron. Soc., 70, 129-140, 1982.

Gordon, R. G. and D. Jurdy, Cenozoic global plate motions, $J$. Geophys. Res., 91, 12,389-12,406, 1986.

Harrison, C. G. A., R. D. Jarrard, V. Vacquier and R. L. Larson, Palaeomagnetism of Cretaceous Pacific seamounts, Geophys. J. R. Astron. Soc., 42, 859-882, 1975.

Heinemann, J., J. Stock, R. Clayton, K. Hafner, S. Cande and C. Raymond, Constraints on the proposed Marie Byrd LandBellingshausen plate boundary from seismic reflection data, J. Geophys. Res., in press, 1999.

Jurdy, D. M. and R. Van der Voo, A method for the separation of true polar wander and continental drift, including results for the last 55 m.y., J. Geophys. Res., 79, 2945-2952, 1974.

Jurdy, D. M. and R. G. Gordon, Global plate motions relative to the hot spots 64 to $56 \mathrm{Ma}, J$. Geophys. Res., 89, 99279936, 1984.

Jurdy, D. M., Reference frames for plate tectonics and uncertainties, Tectonophysics, 182, 373-382, 1990.

Kono, M., Paleomagnetism of DSDP leg 55 basalts and implications for the tectonics of the Pacific plate, Initial Rep. Deep Sea Drill. Proj., 55, 737-752, 1980.

Lawver, L. A. and Gahagan, L., Constraints on timing of extension in the Ross Sea region, Terra Ant., 1, 545-552,1994.

Lonsdale, P., Geography and history of the Louisville hotspot chain in the southwest Pacific, J. Geophys. Res., 93, 30783104, 1988.

Mayes, C. L., L. A. Lawver and D. T. Sandwell, Tectonic history and new isochron chart of the South Pacific, $J$. Geophys. Res., 95, 8543-8567, 1992.

Minster, J. B. and T. H. Jordan, Present-day plate motions, J. Geophys. Res., 83, 5331-5354, 1978.

Molnar, P., T. Atwater, J. Mammerickx and S. M. Smith, Magnetic anomalies, bathymetry and tectonic evolution of the South Pacific since the Late Cretaceous, Geophys. J. R. Astron. Soc., 49, 383-420, 1975.

Molnar, P. and J. Stock, Relative motions of hotspots in the Pacific, Atlantic, and Indian oceans since Late Cretaceous time, Nature, 327, 587-591, 1987.

Morgan, W. J., Convection plumes in the lower mantle, Nature, $230,42-43,1971$.

Morgan, J., Hotspot tracks and the opening of the Atlantic and Indian oceans, in Oceanic Lithosphere, (The Sea, vol. 7), edited by C. Emiliani, pp.443-487, Wiley-Interscience, New York, 1981.

Morgan, J. P. and W. H. F. Smith, Flattening of the sea-floor depth-age curve as a response to asthenopsheric flow, Nature, 359, 524-527, 1992.

Müller, R. D., J-Y. Royer and L. A. Lawver, Revised plate motion relative to the hotspots from combined Atlantic and Indian Ocean hotspot tracks, Geology, 21, 275-278, 1993.

National Geophysical Data Center, ETOPO-5 bathymetry/topography data, Data Announcement 88-MGG-02, NOAA, U.S. Dept. Commerce, Boulder, CO, 1988.

Olson, P., Hot spots, swells and mantle plumes, I:n Ryan, M.P., ed., Magma transport and Storage, John Wiley \& Sons Ltd., pp. 33-51, 1987.

Petronotis, K. E., and D. M. Jurdy, Pacific plate reconstructions and uncertainties, Tectonophysics, 182, 383-391, 1990.

Petronotis, K. E., R. G. Gordon and G. D. Acton, Determining paleomagnetic poles and anomalous skewness from marine magnetic anomaly skewness data from a single plate, Geophys. J. Int., 118, 1992.

Petronotis, K. E., R. G. Gordon and G. D. Acton, A 57 Ma paleomagnetic pole determined from a skewness analysis of crossings of marine magnetic anomaly $25 \mathrm{R}$, Geophys. J. Int., 118, 529-554, 1994.

Petronotis, K. E. and R. G. Gordon, A Maastrichtian paleomagnetic pole for the Pacific plate determined from a skewness analysis of marine magnetic anomaly 32, Geophys. J. Intl., 139, 227-247, 1999.

Ratcliff, J. T., D. Bercovici, G. Schubert and L. Kroenke, Mantle plume heads and the initiation of plate tectonic reorganizations, Earth Plan. Sci. Lett., 156, 195-207, 1998.

Richards, M. A. and R. W. Griffiths, Deflection of plumes by mantle shear flow: experimental results and a simple theory, Geophys. J. R. Astron. Soc., 94, 367-376, 1988.

Royer, J-Y. and D. T. Sandwell, Evolution of the eastern Indian Ocean since the Late Cretaceous- constraints from Geosat altimetry, J. Geophys. Res., 94, 13,755-13,782, 1989.

Royer, J-Y., P. Patriat, H. W. Bergh and C. Scotese, Evolution of the southwest Indian ridge from the Late Cretaceous (anomaly 34) to the middle Eocene (anomaly 20), Tectonophysics, 155, 235-260, 1988. 
Royer, J.-Y. and T. Chang, Evidence for relative motions between the Indian and Australian plates during the last 20 Myr from plate tectonic reconstructions: Implications for the deformation of the Indo-Australian plate, J. Geophys. Res., 96, 11,779-11,802, 1991.

Royer, J-Y., R. G. Gordon, C. DeMets and P. R. Vogt, New limits on the motion between India and Australia since chron 5 (11 Ma) and implications for lithospheric deformation in the equatorial Indian Ocean, Geophys. J. Int., 129, 41-74, 1997.

Sandwell, D. T and W. H. F. Smith, Global marine gravity from ERS-1, Geosat and Seasat reveals new tectonic fabric, EOS Trans. Amer. Geophys. Union, 73, 133, 1992.

Schouten, H. and S. C. Cande, Palaeomagnetic poles from marine magnetic anomalies, Geophys. J. R. Astron. Soc., 44, 567-575, 1976.

Solomon, S.C. and N. H. Sleep, Some simple physical models for absolute plate motions, J. Geophys. Res., 79, 2557-2567, 1974.

Steinberger, B. and R. J. O'Connell, Advection of plumes in mantle flow: implications for hotspot motion, mantle viscosity and plume distribution, Geophys. J. Int., 132, $412-$ 434, 1998.

Stock, J. and P. Molnar, Revised history of early Tertiary plate motion in the southwest Pacific, Nature, 325, 495-499, 1987.

Suarez, E. and P. Molnar, Paleomagnetic data and pelagic sediment facies and the motion of the Pacific plate relative to the spin axis since the Late Cretaceous, J. Geophys. Res., 85, 5257-5280, 1980.

Tarduno, J. A. and R. D. Cottrell, Paleomagnetic evidence for motion of the Hawaiian hotspot during formation of the Emperor Seamounts, Earth Plan. Sci. Lett., 153, 171-180, 1997.

van Andel, T. H., Cenozoic migration of the Pacific plate, northward shift of the axis of deposition, and paleobathymetry of the central equatorial Pacific, Geology, 1, 507-510, 1974.

Wessel, P. and W. H. F. Smith, Free software helps map and display data, EOS Trans. Amer. Geophys. Union, 72, 441-445, 1991.

Wessel, P., and L. Kroenke, A geometric technique for relocating hotspots and refining absolute plate motions, Nature, 387, 365-369, 1997.

Wilson, T. J., Cenozoic transtension along the Transantarctic Mountains-West Antarctic rift boundary, southern Victoria Land, Antarctica, Tectonics, 14, 531-545, 1995.

Steven C. Cande, Scripps Institution of Oceanography, La Jolla, CA 92093-0215, Carol A. Raymond, Jet Propulsion Laboratory, Mail Stop 183-501, 4800 Oak Grove Drive, Pasadena, CA 91109-8099, Joann M. Stock, Seismological Laboratory, Mail Stop 252-21, California Institute of Technology, Pasadena, CA 91125. 